in the forebears must be - and this also is affirmed by Stier-very much larger than can be easily proved by direct statistics.

It would appear, then, that from the cases reported that this trend when present in the stock may produce in the few right-handed individuals of the sinistral stock a condition of brain similar to their collateral relatives and ancestors, with the result that the speech area in such persons becomes developed in an ectopic position. Likewise a left-handed person occurring eccentrically in a righthanded stock is dominated by the trend of that stock rather than by his own individual peculiarities. ${ }^{19}$

These matters would seem to be of small enough practical importance, but one may suggest that the considerations in favor of and against cranial operative procedures are not infrequently influenced by the fear of destruction of the areas governing the function of speech. On this account, apart from the academic interest of the question, it behooves us to record any facts seeming to assist us to increased accuracy of endeavor.

\title{
CIRCUMSCRIBED CYSTS OF THE LEPTOMENINGES, WITH THE REPORT OF A SUCCESSFUL OPERATIVE CASE.
}

\author{
By Frederic M. Hanes, M.A., M.D., \\ PROFESSOR OF THERAPEUTICS, MEDICAL COLLEGE OF VIRGINIA, RICHMOND, VIRGINIA. \\ AND \\ A. M. Wilitis, M.D., \\ CLINICAL PROFESSOR OF SURGERY, MEDICAL COLLEGE OF VIRGINIA, RICHMOND, VIRGINIA.
}

Circumscribed cystic spinal meningitis is not an uncommon cause of spinal cord compression, and since operative interference offers prompt relief from an otherwise progressive and irreparable injury, its early recognition is of great importance. Among 45 cases operated upon for suspected tumor of the cord by Krause, 1 cystic meningitis or, as he terms it, arachnitis adhesiva circumscripta was found in 11, or about 24 per cent. Despite the fact, however, that cystic spinal meningitis can no longer be regarded as a rarity, the literature upon the subject is still very scanty and a general knowledge of the condition is lacking.

Spiller" wrote in 1908: "A collection of the clear fluid in a cyst

19 July 26, 1916. Man, aged thirty-one years. Seen in Bellevue Hospital. Almost complete palsy of left face and left arm, much weakness in left leg; left homonymous hemianopia; left hemianesthesia. Probable luetic cerebral thrombosis. Left-handed from infancy; prefers to write with the left hand. Never any speech difficulty even immediately following onset. Patient is the only left-handed individual in a family of seven, and in a large connection the members of which are well known to him.

1 Surgery of the Brain, iii, 1055 (Rebman, New York).

2 Am. Jour. Med. Sc., 1909, exxxvii, 95. 
of the spinal pia-arachnoid is a condition little known in America, as only one case occurring in this country is on record (Spiller, Musser, and Martin), and only a few are found in German literature. So far the French and English journals contain no examples." Since this was written several excellent papers have appeared. The first satisfactorily reported case was that of Spiller, Musser, and Martin, ${ }^{3}$ in 1903. Since then instances of the affection have been reported by Krause, ${ }^{4}$ Oppenheim, ${ }^{5}$ Bruns, ${ }^{6}$ de Montet, ${ }^{7}$ Mendel and Adler, ${ }^{8}$ Horsley, ${ }^{9}$ Bliss, ${ }^{10}$ Weisenburg and Müller, ${ }^{11}$ Munro, ${ }^{12}$ and Mills. ${ }^{13}$ Krause, in his Surgery of the Brain and Cord (translation, Rebman, New York), gives very clear illustrations of the condition. That the disease is by no means so rare as the literature would indicate is attested by the experience of Munro, ${ }^{14}$ who after reading the description of a case was able to report five instances from his own previous experience in which no satisfactory diagnosis had been registered at the time of operation. One unfamiliar with the condition might easily fail to recognize it at operation.

Skoog ${ }^{15}$ has recently reported two instances of leptomeningeal cysts, and reviews the literature. He makes the absolutely incorrect assertion that only four instances of simple uncomplicated cysts of the pia-arachnoid have been recorded, basing his statement upon what he terms a "thorough search of the literature." And yet the author fails even to mention the perfectly typical case that Weisenburg so fully recorded in this JournaL in 1910. Skoog apparently has undisclosed criteria of his own as to just what constitutes a Jeptomeningeal cyst, for he discredits Munro's five cases with the simple remark that "it is necessary to reject his reported cases." The unbiased reader of Munro's article will not, I think, feel the same necessity that Skoog so cryptically confesses.

Before proceeding to a discussion of circumscribed cystic spinal meningitis a very typical instance of the affection which recently came under our observation will be briefly reported:

CASE H1STORY.-Progressive paralysis of both legs for one year; no pain; paresthesia of legs; anesthesia below mid-abdomen; bladder disturbances; operation and evacuation of localized leptomeiningeal cyst; marked improvement.

3 Univ. of Penn. Med. Bull., 1903, xvi, 27.

${ }^{4}$ Verhandl. d. Dentsch. Gesellsch. f. Chir., 1907, xxxvi, 598.

5 Beitrage zur Diagnostik und Therapie der Geschwulste im Bereich des Centralen Nervensystems, Berlin, 1907.

6 Berl. klin. Wchnschr., 1908, p. 1753.

7 Cor.-Bl. f., schweiz. Acrzte, 1908 , p. 698.

8 Berl. klin. Wchnschr., 1908, xlv, 1596.

${ }^{9}$ Brit. Med. Jour., 1909, i, 513.

10 Jour. Am. Med. Assn., 1909, liii, 885.

11 Am. Jour. Mro. Sc., 1910., cxl, 719, No. 5.

12 Surg., Gynec. and Obst., 1910, x, 235.

${ }_{13}$ Jour. Nerv. and Ment. Dis., 1910, xxxvii, 529.

14 Loc. cit.

${ }_{15}$ Jour. Am. Med. Assn., 1915, lxv, 394. 
The patient, J. K., a colored man, aged twenty-six years, was brought to the Virginia Hospital because of complete paralysis of both lcgs.

The family and past histories were devoid of importance. He denied gonorrheal or syphilitic infection, and up until the present trouble had been healthy. No symptoms of tuberculosis.

About fifteen months ago the right leg began to grow weak and felt a little stiff. This was followed in a few weeks by similar symptoms in the left leg. His gait became unsteady and he staggered "like a drunken man." Three months after onset his legs had become so weak that he was forced to remain in bed most of the time. Except when assisted into a chair he has been in bed for the past twelve months.

The patient is positive that he has never suffcred any pain during his present illness. No history of anything resembling root-pain can be elicited even with strong suggestion. He has had numbness of both legs from time to time, and is aware that the sense of touch is at present diminished in the legs.

During the past year he has had periods of frequency and urgency of urination, but has never been incontinent. At present he says he notices no abnormality of the bladder or rectal functions.

Physical Examination. The patient is a thin, poorly nourished man, lying in the dorsal decubitus, with both legs strongly flexed on the thighs. The head, neck, chest, and abdomen present no features of importance. No general or local adenopathy.

Neurological Examination. The pupils are equal in size, regular in outline, and both react actively to light and during accommodation. No nystagmus, strabismus, or diplopia. Vision good. Fundi negative. Hearing is acute and equal in the two ears. 'The other cranial nerves are likewise normal.

As the patient lies in bed the legs are constantly flexed, and upon the slightest stimulation they pass into a state of tonic spasm. All the muscles of the legs are involved in this spasm, and the abdominal muscles are rigid and spastic. Both legs are almost completely paralyzed; he can move them slightly after great effort, but cannot in any way control them. Upon attempting passively to flex and extend the patient's legs a condition of great spasticity is encountered which prevents any but the very slowest manipulations. The legs cannot be completely extended.

Sensation to touch, pain, heat, and cold is deficient over the legs and trunk up to the level of the ninth dorsal skin segment. The upper thighs and trunk are not completely anesthetic, but the patient is able to indicate with constancy and accuracy the line below which sensation is impaired. On the legs and feet, sensation is practically abolished. The tests for muscle and joint sense are untrustworthy because of the great degree of spasticity, but from passive movement of the toes it seems impaired. 
The reflexes are normal in the upper limbs, but all deep reflexes are exaggerated in the legs. There is double ankle clonus, and the Babinski reflex is bilatcrally positive. Bceausc of the board-like spasticity of the abdominal muscles the superficial abdominal reflexes cannot be satisfactorily tested.

There is no sphincter disturbances at present. The patient is completely bed-ridden. 'The temperature and pulse are normal.

A spinal puncture was performed and 8 c.c. of fluid under apparently diminished pressure was obtained. The fluid had a distinet yellowish tinge, though not frankly yellow in color. The cell count showed the presence of three lymphocytes to the cubic millimeter. The Noguchi globulin reaction indicated the presence of a very marked excess of protein material. With the heat and acetic acid test a heavy, floecular precipitate formed in the fluid. The significance of this picture-xanthochromia, protein excess with low cell count--has been discussed recently by one of us in this Journal (Hanes, 1916, clii, 66). Suffice it to say that its presenee strengthened the probable diagnosis of spinal cord tumor. The Wassermann reaction was negative in both blood and spinal fluid.

The clinical diagnosis of extramedullary tumor compressing the spinal cord was registered, and under ether anesthesia lamineetomy was performed. The dura was exposed at the level of the fifth, sixth, and seventh dorsal vertebræ. It lid not pulsate. Upon opening the dura at the level of the sixth dorsal vertebre a cherrysized translucent, delicate-walled cyst presented at once in the dorsal incision. This was incised with the escape of perfectly clear, colorless fluid, and the cyst structure collapsed. There was apparently only one cyst. The spinal canal was explored thoroughly above and below, but no other tumor mass could be found. 'The cord seemed flattened and somewhat eompressed by the cyst, and the vessels below the level of the cyst were distinetly engorged and tortuous.

The dura was sutured and the wound closed. Healing was rapid, and on the eighth day after the operation was complete.

The improvement in the condition of the patient was immediate and quite rcmarkable. On the day following the operation he could move the legs with considerable certainty, and this improvement continued until on the tenth day following the operation he was able to stand for a moment or two alone. Since this time there has been a gradual gain in the strength and control of the legs, but improvement has been slower than perhaps would have been the case had the patient's circumstances permitted efficient physical therapy. The muscles of both legs are still spastic, though much less so than before operation, and the Babinski reflex is still bilaterally positive.

Six weeks after the operation lumbar puncture was again performed. The fluid was now quite normal in appearanec, without 
a trace of color. There were four cells to the cubic millimeter, with only a faint trace of proteid, as contrasted with the former great excess. This finding proves incontestably that the xanthochromia and protein excess present in the spinal fluid before operation were caused by the cystic tumor which had formed a cul-de-sac below its site of growth. Cpon restoring the integrity of the canal the fluid promptly resumed its normal character.

The exact etiology of circumseribed cystic formations in the spinal leptomeninges is uncertain. The pia-arachnoid spaces of the brain and cord form a true serous cavity analogous to the pleural and peritoneal spaces, and it is reasonable to assume, in view of the frequency of inflammatory adhesions in other serous cavities, that the delicate leptomeninges, as the result of either septic or aseptic inflammatory processes, form adhesions which may produce single or multiple cysts. The histological structure of the trabeculated pia-arachnoid membrane would seem to favor such a process. The occurrence of aseptic meningeal inflammations of various degrees, from meningismus to true purulent meningitis, with thousands of leukocytes in the spinal fluid (Zabel ${ }^{16}$ ), is not sufficiently recognized. Such aseptic inflammatory processes might easily lead to leptomeningeal adhesions and cyst formations.

Trauma has closely preceded the development of certain cases of cystic meningitis, and several writers mention it as an etiological factor. ${ }^{17} 1819$ We are inelined to believe that traumata by the production of small hemorrhagic effusions into the leptomeninges may cause toxic inflammation, with consequent adhesions. That inflammatory processes in structures in the neighborhood of the pia-arachnoid, such as spinal tuberculosis or osteomyelitis, may ultimately lead to localized leptomeningitis is well recognized. In general it scems fair to say that any process, either septic or aseptic, which causes localized meningeal inflammation, may through the formation of adhesions, produces cysts of the piaarachnoid.

The pathological condition, as scen at operation, consists in the presence of one or more cysts, with very delicate walls. When the dura is incised the thin-walled, translucent, cystic structure protrudes under the pressure of the contained fluid. Upon puncturing the cyst the walls collapse and become inconspicuous. If in opening the dura one should puncture the pia-arachnoid cyst it is easily understandable that the condition might pass unrecognized. Certainly from some of the deseriptions published, where "upon opening the dura a large quantity of fluid escaped under pressure," one is forced to conclude that a cyst was opened along with the dura.

${ }_{16}$ Mitt. a. d. Grenzge. d. Med. u. Chir., 1913, xxv, 211.

${ }_{17} \mathrm{Mendel}$ and Adler, loc. eit.

${ }^{19}$ Bliss, M. A., loc. cit. 
The cord shows the effect of the pressure which the cystic tumor has cxerted, being somewhat flattened and compressed, with engorgement of the pial vessels. In our case the veins of the cord distal to the site of the cystic obstruction were markedly congested and tortuous, and we are convinced that this obstruction to the venous flow of blood accounts for the curious condition of the spinal fluid found in this case. The fluid was yellowish, with only 3 cells to the cubic millimeter; but it contained an enormous excess of protein, and coagulated on standing. In short, the fluid obtained by lumbar puncture had the characteristics of a transudate such as is commonly encountered as the result of venous obstruction. Spinal fluids with the characteristics just described are not at all uncommon, and are of very great practical significance, for they always indicate compression of the cord with the formation of a lumbar cul-de-sac.

The symptoms of circumscribed serous meningitis are those of cord tumor. We doubt the possibility of making a differential diagnosis betwecn extramedullary tumor of the cord and cyst of the pia-arachnoid. Cysts, indeed, when circumscribed are tumors capable of exerting pressure which causes almost complete transverse blocking of the cord functions. We have never seen morc intense spasticity or more complete paralysis than was present, for example, in our case, even in long-standing cases of extramedullary neoplasm.

Horsley ${ }^{20}$ enumerates some eight differential points which he thinks are of service in the diagnosis of circumscribed scrous meningitis. Horsley, however, has included in his paper certain cases which cannot properly be regarded as instances of circumscribed cystic meningitis, but are rather examples of meningomyelitis. Aside from this, moreover, one of us while working at the National Hospital for Paralyzed and Epileptics in London had the opportunity of studying carefully a case of circumscribed cystic meningitis which violated practically all of Horsley's differential points. Horsley operated for cord tumor and found a circumscribed cyst. Oppenheim ${ }^{21}$ thinks cysts of the pia-arachnoid cannot be differentiated from extramedullary neoplasms. Fortunately, the nced of separating the two conditions does not exist, for both demand precisely the same operative treatment. It is far more important to recognize that both neoplasms and cysts may present most atypical pictures and not to be misled thereby.

The symptoms and signs as reported by various observers consist of pain, disturbances of sensation, paralysis or paresis, abnormality of the reflexes, and sphincter disturbances. These are manifestations of transverse lesions of the cord from whatsoever cause, and in diagnosis one must eliminate syphilitic and tuberculous disease,

${ }^{20}$ Loc, cit.

${ }^{21}$ Lehrbuch der Nervenkrankheiten, 1913, i, 388 (full literature). 
acute meningomyelitis, extramedullary tumors as well as traumatie injuries, sueh as fraeture disloeation of the vertebræ. In the process of differential diagnosis a thorough examination of the spinal fluid is of the greatest value. It is impossible to agree at all with Munro $^{22}$ when he states that "nearly every writer condemns lumbar puneture . . . as an aid to diagnosis except negatively." As we have shown in our case the condition of the spinal fluid was of the greatest positive support in the diagnosis of cord eompression as opposed to meningomyelitis, gumma, or parenchymatous eord lesions.

Pain has been a prominent feature of most of the cases recorded. Our patient denied absolutely having suffered any pain at all. Pain was formerly regarded as an essential clinical feature of spinal cord neoplasms, but we now know that extramedullary tumors may exist with none or only insignificant pain. The same is doubtless true of cystic meningitis.

The treatment of leptomeningeal cysts is wholly surgical. The time is rapidly approaching when exploratory laminectomy will be resorted to with greater frequency than is done at present. The operation is a simple one, easily within the powers of any competent surgeon. The removal of the spinous processes and dorsal laminæ does not materially weaken the spinal column, and the operative wound heals promptly. It is, of course, unnecessary to emphasize that laminectomy should never be performed except with the support of a competent neurological opinion.

\section{THE TREATMENT OF FRACTURE OF THE SPINE.}

By Norman Sharpe, M.D., NEUROLOGICAL SURGEON, NEW YORK POST-GRADUATE HOSPITAL.

THERE has been such an advance in surgical methods the past deeade that conditions which formerly did not warrant surgieal interferenee are now being suecessfully treated.

The reeent developments in cranial and in intestinal surgery are illustrative of the advanees made in surgery in general. 'This is specially true of the progress made in spinal-cord surgery during the last five years. However, as in any new field, progress is hampered by the beliefs and praetises of the past, and that has operated strongly against progress in the rational treatment of spinal fraetures.

Fraeture of the spinal column with damage to the eord or roots is eonsidered, and rightly so, a most serious injury. Though the 